\title{
Menorrhagia due to uterine amyloidosis in familial Mediterranean fever: case-based review
}

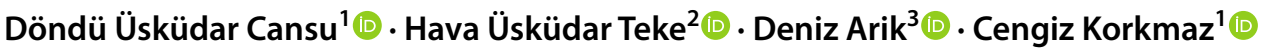

Received: 31 August 2020 / Accepted: 1 October 2020 / Published online: 14 October 2020

(c) Springer-Verlag GmbH Germany, part of Springer Nature 2020

\begin{abstract}
Amyloidosis is described by the deposition of misfolded proteins in the tissues. Amyloidoses are classified into two as systemic and localized. Out of the systemic forms, AL (light chain) amyloidosis is the most prevalent type; however, amyloid A (AA) amyloidosis is more frequently encountered in the rheumatology practice. AA amyloidosis stands out as a major complication of familial Mediterranean fever (FMF). Splenic and renal involvement is more likely in FMF-associated systemic amyloidosis. The involvement of thyroid and adrenal glands has also been described, although infrequently. Amyloidoses have a heterogeneous plethora of clinical manifestations, with certain phenotypes associated with specific amyloid forms. Gynecological amyloidosis is a rare condition. Uterine involvement may occur in a localized fashion or may also arise as a part of systemic involvement, albeit at a lesser ratio. Several cases of uterine AL amyloidosis have been documented so far as an organ involvement in systemic AL amyloidosis. On the other hand, uterine amyloidosis associated with AA amyloidosis has been described merely in one case with rheumatoid arthritis (RA). Here, we presented a 40-year-old female patient with FMF known for 38 years who underwent splenectomy and hysterectomy due to massive splenomegaly, deep anemia, and persistent menometrorrhagia. Histological examinations of materials revealed uterine and splenic AA amyloidosis. This case report is first-of-its-kind to describe FMF-associated uterine AA amyloidosis and also provides a discussion of possible mechanisms of amyloidosis-induced uterine bleeding.
\end{abstract}

Keywords Familial Mediterranean fever · Amyloidosis · Uterine hemorrhage

Döndü Üsküdar Cansu

ducansu@hotmail.com

Hava Üsküdar Teke

havaus@yahoo.com

Deniz Arik

denarik@hotmail.com.tr

Cengiz Korkmaz

ckorkmaz@ogu.edu.tr

1 Division of Rheumatology, Department of Internal Medicine, School of Medicine, Eskişehir Osmangazi University, 26480 Eskişehir, Turkey

2 Division of Hematology, Department of Internal Medicine, Eskişehir Osmangazi University, Eskişehir, Turkey

3 Division of Pathology, Eskişehir Osmangazi University, Eskişehir, Turkey

\section{Introduction}

The amyloidoses are characterized by deposition of fibrillary proteins called amyloid within the tissue, resulting in multiple organ injuries. Among systemic amyloidoses, AL (light chain) remains to be the most commonly diagnosed type of amyloidosis worldwide. Other clinically significant systemic varieties are AA amyloidosis (formerly known as secondary amyloidosis), leukocyte chemotactic factor 2 amyloidosis (ALECT2), and transthyretin amyloidosis (ATTR). AA amyloidosis is a result of chronic inflammatory disorders such as familial Mediterranean fever (FMF) and rheumatoid arthritis (RA). Target-organ involvement differs from the type of amyloidosis. While localized forms involve one or a few organs, the involvement of various organs and tissues is expectable in systemic forms. Any organ except the central nervous system can be a site of AL or AA amyloidosis, the best-known systemic type. Although the kidney, spleen, liver, and heart are more likely affected, amyloid fibrils, in theory, may deposit in any organ or tissue $[1,2]$. 
Amyloidosis is a rare disease. In a study conducted in England, the incidence of systemic amyloidosis in the general population was $0.8 / 100.000$, while the annual incidence of AA amyloidosis was found to be $0.08 / 100.000$ [3]. AA amyloidosis was found in $8.6 \%$ of 2246 patients with FMF in a study conducted in Turkey [4]. Gynecological amyloidosis has also been documented, albeit rarely [5-13]. The majority of reported cases were localized amyloidoses $[5,6]$. Uterine amyloidosis associated with systemic amyloidosis has been described in a few cases, mostly comprised of primary amyloidosis (AL), whereas uterine AA amyloidosis has been reported just in one case who had RA [9-13].

Here, were present an FMF patient presented with massive splenomegaly and renal insufficiency who was diagnosed with systemic AA amyloidosis and upon hysterectomy that was performed due to persistent menometrorrhagia, found out to be the first patient in the medical literature with documented uterine AA amyloidosis. We have also reviewed the barely available previous cases and provided a discussion of possible mechanisms underlying the bleeding due to uterine amyloidosis.

\section{Case presentation}

A 40-year-old female patient complaining of swollen legs, fatigue, and weight loss was admitted to another center. She was referred to our department as she had azotaemia, deep anemia, and a positive history of FMF. Based on queries directed to the patient, we have learned that she had been suffering repetitive episodes of abdominal pain and fever for 2 years of age, she had undergone an appendectomy at the age of 18 , and her maternal uncle and daughter of her maternal aunt also had similar complaints, both of whom were lost due to renal failure. Her medical history indicated that she used to be followed up by our department from 2002 to 2008 with an established diagnosis of FMF (M694 V homozygous mutant) under regular colchicine when she was on regular colchicine, but then has been lost to follow-up for 13 years because of social security issues. She reported visiting the external facility due to abdominal pain and fatigue where deep anemia (hemoglobin $[\mathrm{Hb}]: 7 \mathrm{~g} / \mathrm{dL}$ ) and massive splenomegaly (spleen size: $230 \times 85 \mathrm{~mm}$ ) were determined and, therefore, bone marrow (BM) biopsy was requested which showed an abundance of granulocytic cells and was tested negative for JAK2 V617F mutation. Further background information included prior transfusion of 5 units of erythrocyte suspension (ES) due to deep anemia, and administration of anti-acidosis treatment as she had metabolic acidosis as well as elevated creatinine level. Once the patient was referred to our department, she was questioned about deep anemia and stated that she was suffering menometrorrhagia with an onset of approximately 1 month ago. Transvaginal ultrasound (US) revealed free abdominal fluid and a simple cyst of $32 \times 23 \mathrm{~mm}$ in the left adnexal area. Endometrial biopsy was collected as a part of menometrorrhagia-related work-up and results were normal. As the patient had $3.9 \mathrm{~g} /$ day of proteinuria and elevated levels of creatinine, chronic kidney disease (CKD) induced by secondary amyloidosis was considered for the patient. We have consulted with the department of hematology with patient findings of $\mathrm{Hb}: 6.9 \mathrm{~g} /$ dL, platelet count [PLT]: $108,000 / \mathrm{mm}^{3}$, and massive splenomegaly. They recommended BM biopsy previously collected by the external center should be stained for amyloids, paroxysmal nocturnal haemoglobinuria (PNH) panel should be studied, and a positron emission tomography (PET-CT) scan should be conducted to help differential diagnosis of lymphoma. The patient was instructed to have these exams done in an outpatient setting and thus discharged to home. Meanwhile, the COVID-19 pandemic has emerged, and she could not attend her medical appointments. Two months later, as she experienced syncope, the patient was hospitalized at the intensive care unit (ICU) of an external center where $\mathrm{Hb}: 2 \mathrm{~g} / \mathrm{dL}$ was measured, and ES transfusion was delivered.

When the patient returned to our department, she had bicytopenia (anemia + thrombocytopenia, renal failure (blood urea nitrogen [BUN]: $76.3 \mathrm{mg} / \mathrm{dL}$, creatinine [Cr]: $7.54 \mathrm{mg} / \mathrm{dL}$ ) and metabolic acidosis. She underwent haemodialysis and received ES transfusion. Both protein electrophoresis and PNH panel were normal. In the PET-CT image, the spleen was extremely enlarged, and a diffuse increase was noted in gastric wall [standardized uptake value (SUVmax): 10.8]. In the endoscopic examination, diffuse hyperaemia and oedema were seen along the mucosa and walls of the gastric corpus and antrum. Samples were collected for a gastric biopsy which resulted as AA amyloidosis and chronic gastritis. Daily 2-3 units of ES transfusion were required to manage severe menometrorrhagia of the patient. In our opinion, thrombocytopenia was caused by hypersplenism, and anemia was induced by bleeding and hypersplenism. Provisional diagnoses of amyloidosis-associated massive splenomegaly and hypersplenism were made, and splenectomy was decided. Department of Gynecology initially employed hormone therapy for persistent menometrorrhagia without success. As bleeding worsened, surgery was decided. Prothrombin time, activated partial thromboplastin time, and international normalized ratio; fibrinogen, and factor VII, VIII, IX, XI, and XIII values of the patient were lying within their respective normal range, but platelet aggregation was disrupted as measured by ristocetin cofactor assay (RCof) (Factor X testing is not available in our site, therefore was not done). Thus, menometrorrhagia of the patient was attributed to platelet dysfunction and thrombocytopenia with a likely contribution of amyloidosis. The patient underwent splenectomy + hysterectomy and bilateral 
salpingo-oophorectomy in a single operating session. In the pathological examination, the left ovary and spleen were stained with crystal violet and Congo red which produced a staining pattern suggesting amyloids, and amyloid A staining was positive. Suspecting amyloid deposition also in the uterus, we applied uterine amyloid staining. Crystal violet staining was consistent with amyloid deposits at superficial myometrial vessel walls (Figs. 1, 2, 3). Moreover, amyloid deposits in patches were indicated at endometrial vessel walls. No postoperative complications were observed. Following the splenectomy, thrombocytopenia of the patient recovered. She was initiated on anakinra $100 \mathrm{mg} /$ every other day subcutaneous for FMF-associated diffuse secondary amyloidosis. The patient had no active complaints in the postoperative 2 nd month and 1.5 months after the anakinra treatment and the haemodialysis program was continued. The acute phase response and hemogram of the patient returned to normal completely. However, proteinuria was continued. (Clinical and laboratory findings of the patient are given in Table 1.)

\section{Search approach}

This review was carried out in line with the search approach suggested for narrative studies [14]. To find the other similar cases with AA amyloidosis of the uterine tissue with an underlying rheumatological disease in the literature without limitation for start date until July 2020, we searched databases PubMed, Web of Science, Scopus, and Google Scholar using MeSH terms "uterine hemorrhage" [AND] "amyloidosis". Non-English publications, papers describing cases not associated with any rheumatological disorders, and cases diagnosed with amyloidosis types other than AA

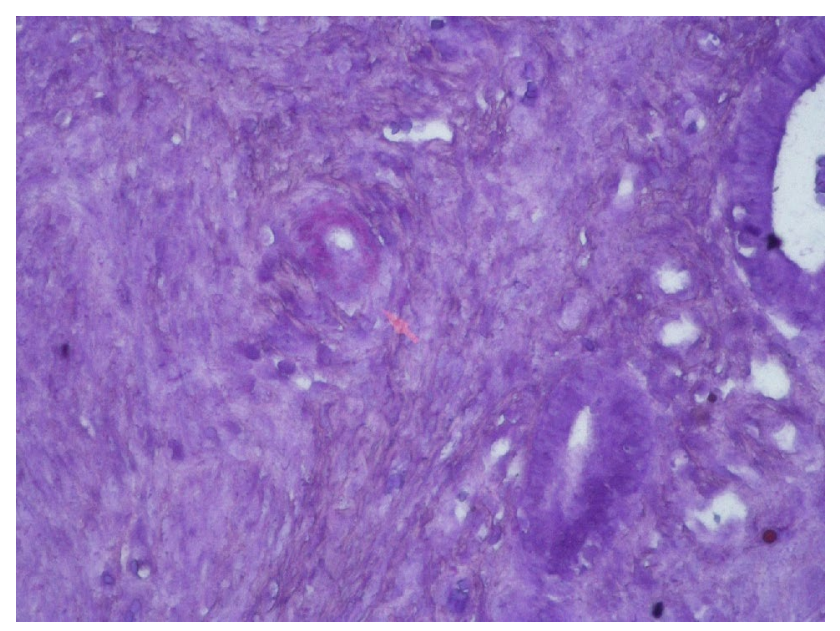

Fig. 1 Crystal violet staining suggesting amyloid deposits at superficial myometrial vessel walls (arrow). Endometrial glands are visible on the right (crystal violet $\times 200$ )

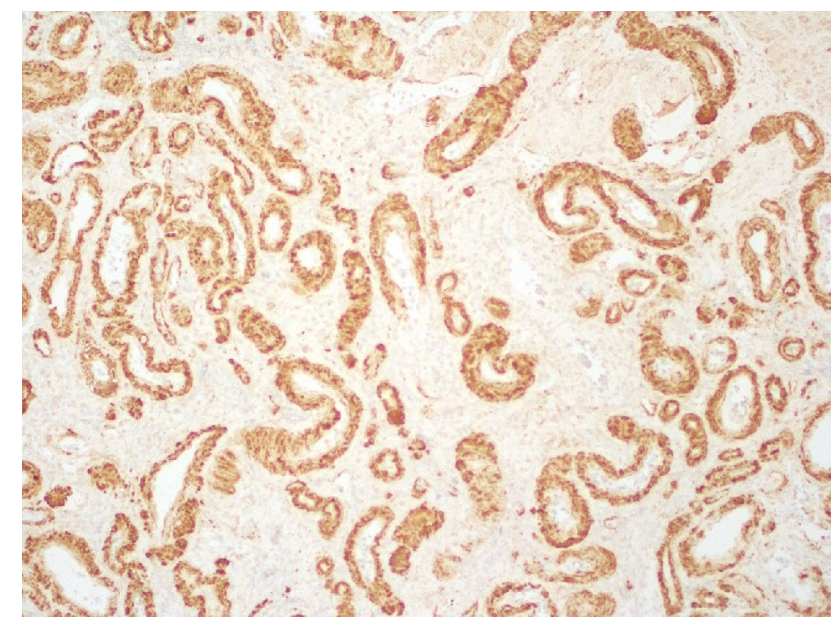

Fig. 2 Immunohistochemical assay tested positive for amyloid A throughout vessel walls of the spleen parenchyma $(\times 100)$

amyloidosis were excluded from this study. Our search for uterine AA amyloidosis concerning a rheumatological disease produced only one result [13]. Along with our case, we provided a discussion of that single case.

\section{Discussion}

Clinical characteristics of amyloidosis depend on the specific type of offending fibrillar amyloid. AL amyloidosis, in particular, may cause deposition in multiple vital organs, and leads to various kinds of clinical syndromes such as cardiomyopathy, proteinuria, macroglossia, autonomic dysfunction, and neuropathy. AA amyloidosis is linked with various chronic inflammatory disorders, chronic infections,

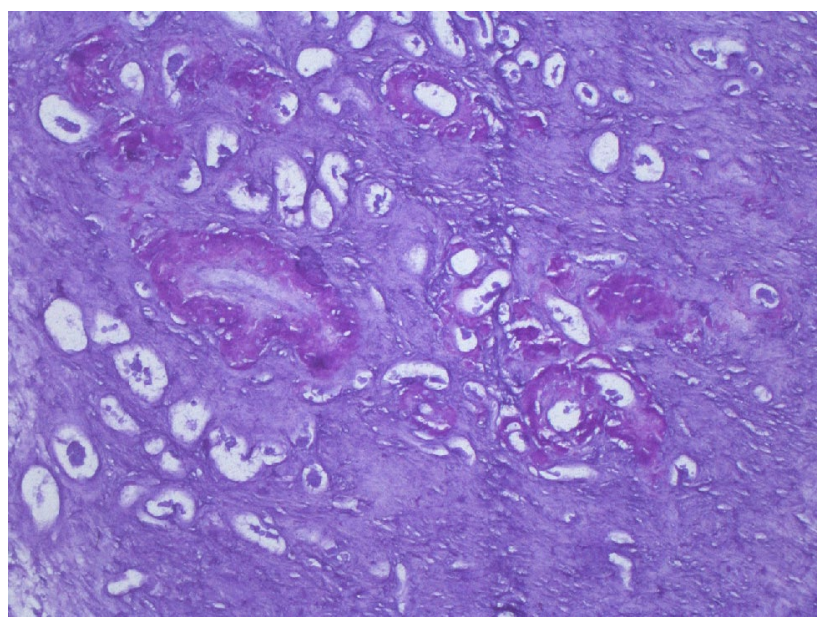

Fig. 3 Deposition observed in fuchsia at the ovarian parenchymal vessel wall as stained by crystal violet $(\times 200)$ 
Table 1 Clinical and laboratory findings of our patient

\begin{tabular}{|c|c|c|c|c|c|c|c|}
\hline & $\begin{array}{l}\text { First admission } \\
\text { to rheumatology } \\
\text { (when FMF was } \\
\text { diagnosed) }\end{array}$ & $\begin{array}{l}\text { 21th years of } \\
\text { FMF disease }\end{array}$ & $\begin{array}{l}\text { 24th years of } \\
\text { FMF disease }\end{array}$ & $\begin{array}{l}\text { 38th years of } \\
\text { FMF disease } \\
\text { (after } 13 \text { years } \\
\text { without follow- } \\
\text { up) }\end{array}$ & $\begin{array}{l}\text { Admission with } \\
\text { menorrhagia }\end{array}$ & $\begin{array}{l}3 \text { days after } \\
\text { splenectomy } \\
\text { and hysterec- } \\
\text { tomy }\end{array}$ & $\begin{array}{l}2 \text { months after } \\
\text { surgery }\end{array}$ \\
\hline Date & 22 August 2002 & 13 March 2003 & 26 June 2007 & 9 March 2020 & 12 June 2020 & 2 July 2020 & September 2020 \\
\hline Age, years & 22 & 23 & 27 & 40 & 40 & 40 & 40 \\
\hline $\mathrm{Hb}, \mathrm{g} / \mathrm{dL}$ & 8.8 & 13.8 & 10 & 7.7 & 4.8 & 9.5 & 14 \\
\hline $\mathrm{WBC}, \mathrm{mm}^{3}$ & 6400 & 6500 & 5800 & 6550 & 12,590 & 12,900 & 8470 \\
\hline PLT, $\mathrm{mm}^{3}$ & 468,000 & 246,000 & 381,000 & 107,000 & $\begin{array}{c}101,000 \text { (lowest } \\
\text { value } 55,000)\end{array}$ & 121,000 & 344,000 \\
\hline $\mathrm{ESR}, \mathrm{mm} / \mathrm{h}$ & 78 & 9 & 27 & 97 & 104 & - & 16 \\
\hline CRP, mg/dL & 0.2 & 0.1 & 0.92 & 25.4 & 50.1 & 65.9 & 0.9 \\
\hline BUN, mg/dL & 10 & 9 & - & 60.5 & 76.2 & 25.4 & 48 \\
\hline $\mathrm{Cr}, \mathrm{mg} / \mathrm{dL}$ & 0.62 & 0.64 & 0.52 & 4.38 & 7.54 & 3.54 & 5.5 \\
\hline AST, IU/L & 23 & 16 & 14 & 9 & 5 & 60 & 12 \\
\hline ALT, IU/L & 25 & 16 & 13 & 5 & 5 & 14 & 12 \\
\hline LDH, IU/L & 311 & - & - & 317 & 236 & - & 272 \\
\hline $\begin{array}{l}\text { Other labora- } \\
\text { tory examina- } \\
\text { tions }\end{array}$ & $\begin{array}{l}\text { FMF gene muta- } \\
\text { tion: M694V } \\
\text { homozygous } \\
\text { positive } \\
\text { Ferritin: } \\
13.7 \mathrm{ng} / \\
\text { mL (iron } \\
\text { deficiency } \\
\text { anemia) } \\
\text { Urinalysis: pro- } \\
\text { tein negative }\end{array}$ & $\begin{array}{l}\text { Urinalysis: pro- } \\
\text { tein negative }\end{array}$ & $\begin{array}{l}\text { Urinalysis: pro- } \\
\text { tein negative } \\
\text { Abdomi- } \\
\text { nal USG: } \\
\text { spleen axis } \\
\text { is } 15.7 \mathrm{~cm} \text {, } \\
\text { follicle cyst in } \\
\text { the left ovary }\end{array}$ & $\begin{array}{l}\text { Total protein: } \\
6.5 \mathrm{~g} / \mathrm{dL} \\
\text { Albumin: } \\
3.46 \mathrm{~g} / \mathrm{dL} \\
\text { Parathyroid hor- } \\
\text { mone: } 226 \mathrm{pg} / \\
\text { mL }(15-65) \\
\text { Urinalysis: }+3 \\
\text { protein } \\
\text { Ferritin: } 201 \mathrm{ng} / \\
\text { mL } \\
\text { 24-h urine } \\
\text { proteinuria: } \\
3.9 \text { g/day }\end{array}$ & $\begin{array}{l}\text { Total protein: } \\
5.92 \\
\text { Albumin: } 3.54 \\
\text { Potassium: } \\
6.08 \mathrm{mEq} / \mathrm{L}\end{array}$ & - & $\begin{array}{l}\text { Total protein: } \\
7.58 \\
\text { Albumin: } 4.4 \\
\text { 24-h urine } \\
\text { proteinuria: } \\
7 \mathrm{~g} / \text { day }\end{array}$ \\
\hline Treatments & $\begin{array}{l}\text { Colchicine } \\
\text { Iron tablet }\end{array}$ & Colchicine & Colchicine & Colchicine & $\begin{array}{l}\text { Colchicine } \\
\text { Proton pump } \\
\text { inhibitor } \\
\text { Metoclopramide } \\
\text { Hemodialysis }\end{array}$ & $\begin{array}{l}\text { Colchicine } \\
\text { Proton pump } \\
\text { inhibitor } \\
\text { Hemodialysis } \\
\text { Imipenem }\end{array}$ & $\begin{array}{l}\text { Colchicine } \\
\text { Anakinra } \\
\text { Haemodialysis }\end{array}$ \\
\hline
\end{tabular}

$H b$ hemoglobin, $W B C$ white blood cell, $P L T$ platelet, ESR erythrocyte sedimentation rate, $C R P$ C-reactive protein, $A S T$ aspartate aminotransferase, $A L T$ alanine aminotransferase, $L D H$ lactate dehydrogenase, $B U N$ blood urea nitrogen, $C r$ creatinine, $F M F$ familial Mediterranean fever, $U S G$ ultrasonography

and rarely with neoplasms [15]. Systemic amyloidosis is an important disease that can lead to dysfunction in vital organs, deterioration in quality of life, and death. AA amyloidosis is also an important life-threatening complication in the course of rheumatologic diseases by causing morbidity and mortality [16]. AA amyloidosis is the main complication of FMF. Amyloidosis risk factors in FMF cases are male gender, and presence of arthritis, M694V and serum apolipoprotein A (SAA) A/A homozygosity, and familial amyloidosis history. The typical phenotype of AA amyloidosis includes the involvement of the kidneys, gastrointestinal tract, spleen, and liver, in addition to thyroid and adrenal gland involvement which occurs rarely [17]. The physician should consider the presence of amyloidosis, especially in the presence of proteinuria, hepatomegaly, or splenomegaly in a patient with FMF. Proteinuria and splenomegaly of our patient suggested amyloidosis and the main AA amyloidosis risk factors in our patient were her M694V homozygous status and (possible) family history of amyloidosis.

A scarce number of gynecological amyloidosis cases have been reported in the literature. Of them, the majority is in localized form. Affected sites were described as uterus, vagina, and cervix $[5,7,8]$. Existing literature suggests uterine (endometrial or myometrial) amyloidosis is a rare condition. Amyloid deposition confined to a site may be associated with several endocrine organs or tumors, taking its origin from the relevant hormones or local protein precursors [2]. Localized uterine amyloidoses have also been 
described in malignancy- or pregnancy-associated fashion $[5,6]$. In our literature search on uterine amyloidoses associated with systemic amyloidosis, as a rare site of involvement compared to other organs, we have identified five cases only. Four of them were AL amyloidosis and just one was AA amyloidosis [9-13]. Two of the AL amyloidosis patients had multiple myeloma and two had primary amyloidosis. Moreover, localized primary amyloidosis formerly reported in one patient was exclusively localized in the uterus [18]. (Causes of uterine amyloidosis according to the literature are summarized in Table 2.) In our search, the single patient with systemic AA amyloidosis was under follow-up for RA. On the other hand, uterine involvement of amyloidosis/amyloid deposits from systemic amyloidosis associated with FMF has not been described so far. Our case is the first-of-its-kind that FMF-induced AA amyloidosis has been observed in the uterus (and ovaries). The previously reported AA amyloidosis was in an RA patient who had undergone endometrial biopsy that was retrospectively explored as a part of an investigation targeting dysfunctional uterine bleeding, and in turn, secondary amyloidosis was eventually diagnosed. That patient had samples collected from other organs before the diagnosis of uterine amyloidosis which were re-stained to indicate that there were no amyloid deposits in liver biopsy, surgical bone, or synovial samples. Later, a gastric biopsy was performed for stomach ulcers which revealed amyloids. Likewise, splenic, ovarian, and gastric biopsies of our patient were accommodating amyloid deposition. Neither of the patients had undergone a renal biopsy, but they were deemed to have renal amyloidosis based on proteinuria and renal insufficiency. Consequently, both patients were suffering diffuse involvement of systemic AA amyloidosis where the uterus was a part of such systemic involvement. Yue et al. have highlighted the importance of exploring the previously obtained tissues before conducting any invasive procedures in a patient with suspected amyloidosis [13]. Once we have encountered the previously documented uterine amyloidosis in our literature search, we have specifically

Table 2 Causes of uterine amyloidosis

Systemic amyloidosis
AL amyloidosis
Primary systemic (AL) amyloidosis
Multiple myeloma
AA amyloidosis (secondary amyloidosis)
Rheumatoid arthritis
FMF
Localized amyloidosis
Localized primary amyloidosis
Pregnancy
Uterine malignancy

requested amyloid staining. Thereupon, staining was done by the pathologist and demonstrated amyloid accumulation in the uterus. (The features of our patient with uterine involvement of AA amyloidosis and the other case in literature are given in Table 3.)

AA amyloidogenesis may take place at various layers of the uterus. While AA amyloidosis in RA patient was detected at perivascular regions of the endometrium, the case with AL amyloidosis was shown to have deposition at myometrial blood vessels $[9,13]$. Amyloids were determined in the superficial myometrium and endometrium in our case. In the AL amyloidosis case described by Copeland et al., on the other hand, a broader involvement covering uterus, cervix, corpus, fallopian tubes, and ovaries as well as the appendix and omentum was mentioned [11]. AA amyloidosis secondary to tuberculosis involving adrenal glands, liver, and kidneys in addition to ovaries which is accompanied by calcification has been described in the literature. However, it was not clarified whether the uterus was involved or not [19]. Similar to the case reported by Copeland et al., we have histopathological evidence of ovarian amyloidosis in our case.

Amyloidosis patients are predisposed to potentially lifethreatening hemorrhage. Pathogenic factors contributing to the amyloidosis-induced bleeding depend on the type and organ deposition of amyloidosis. Abnormal bleedings stemming from amyloidosis may be ascribed to acquired haemostatic abnormalities, abnormal fibrin polymerization and hyperfibrinolysis, platelet dysfunction, and amyloid deposition [20]. Coagulation factor deficiencies are peculiar to $\mathrm{AL}$ amyloidosis patients and have been reported only in specific cases in other amyloidoses, where accumulated amyloid is mainly held responsible for the bleed. Amyloid angiopathy composed of increased fragility of the blood vessels and impaired vasoconstriction may cause bleeding. The exact pathophysiology mechanisms, however, remain unclear. Definite diagnosis of local amyloid deposition can only be made upon a histological investigation [20].

Yue et al. have speculated bleeding suffered by cases with uterine amyloidosis which is arising from the fragile blood vessels inflicted by amyloids [13]. According to Copeland et al., amyloid infiltration of corpus uteri compromises uterine contractions, eventually promoting prolonged bleeding events during menstrual periods [11]. Jongen et al. also proposed that amyloidosis-related bleeding diathesis is most probably caused by increased fragility and impaired contractility of the vasculature (amyloid angiopathy) due to subendothelial amyloid build-up [18]. Although our patient had hypersplenic thrombocytopenia (with an onset of menometrorrhagia while PLT within normal limits), platelet dysfunction was considered due to uraemia and systemic amyloidosis. She had normal results for haemostatic parameters and clotting factors. We believe that platelet dysfunction along with uterine 
Table 3 Characteristics of our patient and other case in the literature

\begin{tabular}{|c|c|c|}
\hline & Our case & Yue et al. [13] \\
\hline Age, years & 40 & 43 \\
\hline Primary disease & FMF & Seropositive, erosive rheumatoid arthritis \\
\hline Primary disease duration, years & 38 & 6 \\
\hline Other findings & $\begin{array}{l}\text { Massive splenomegaly } \\
\text { Proteinuria: } 3.9 \mathrm{~g} / \text { day }\end{array}$ & $\begin{array}{l}\text { Atlantoaxial subluxation } \\
\text { Avascular necrosis } \\
\text { Elevated serum alkaline phosphatase } \\
\text { Proteinuria: } 1.6 \mathrm{~g} / \text { day }\end{array}$ \\
\hline Medications for the disease & Colchicine & Unknown \\
\hline Main gynecological symptom & $\begin{array}{l}\text { Menometrorrhagia (bleeding that lowers the } \\
\mathrm{Hb} \text { level to } 4.8 \mathrm{~g} \text { ) }\end{array}$ & Menorrhagia \\
\hline Duration of menometrorrhagia & 2 months & Unspecified \\
\hline Medical treatment for menometrorrhagia & High dose E2 and PG4 & Unspecified \\
\hline Surgery for menometrorrhagia & $\begin{array}{l}\text { Total abdominal hysterectomy and bilateral } \\
\text { salpingo-oophorectomy due to resistant } \\
\text { menometrorrhagia despite medical treatment } \\
(2 \mathrm{~cm} \text { cyst in the left ovary) }\end{array}$ & Endometrial biopsy only \\
\hline AA amyloidosis involvement site in the uterus & $\begin{array}{l}\text { Involvement in the blood vessels of endome- } \\
\text { trium and myometrium }\end{array}$ & Perivascular involvement of endometrium \\
\hline Non-uterine AA amyloidosis involvement sites & $\begin{array}{l}\text { Stomach, spleen, ovary, and possible renal } \\
\text { (bone marrow insufficient for amyloid assess- } \\
\text { ment) }\end{array}$ & $\begin{array}{l}\text { Stomach, possible renal (liver biopsy negative } \\
\text { for AA amyloidosis) }\end{array}$ \\
\hline Outcome & $\begin{array}{l}\text { AA amyloidosis in uterus (myometrium-endo- } \\
\text { metrium) and left ovary }\end{array}$ & AA amyloidosis in uterus (endometrium) \\
\hline Comment & $\begin{array}{l}\text { In (female) FMF patients, specifically in those } \\
\text { with systemic AA amyloidosis and persistent } \\
\text { menometrorrhagia, uterine AA amyloidosis } \\
\text { should be kept in mind }\end{array}$ & $\begin{array}{l}\text { Since blood vessels infiltrated by amyloid are } \\
\text { known to be fragile, it is possible that the } \\
\text { amyloidosis may have contributed to this } \\
\text { patient's menorrhagia }\end{array}$ \\
\hline
\end{tabular}

$F M F$ familial Mediterranean fever, $H b$ hemoglobin, $E$ estrogen, $P G$ progesterone

amyloid deposition (amyloid angiopathy) was the major risk factor for bleeding in our case. Jongen et al. claim that uterine amyloidosis, despite infrequent, must be included in the differential diagnosis of postmenopausal bleeding [18]. Nevertheless, our patient was of premenopausal age. Therefore, not only postmenopausal bleeding but also treatment-resistant premenopausal menorrhagia warrants considering uterine amyloid deposition, especially in the event of any other organ involvement of systemic amyloidosis.

In conclusion, endometrial amyloid existence may be more common than the currently anticipated and established figures. As we understood from our literature review, which is in line with our own experience, so far, the patients could usually be diagnosed through a retrospective search for amyloid as uterine amyloidosis is not a well-recognized site of involvement. While taking care of any diseases which may cause amyloidosis, rheumatologists should be cautious about possible uterine involvement and ensure that histopathological amyloid testing is carried out at diagnostic samples, particularly in patients presented with other organ involvement and menometrorrhagia.
Author contributions Study concept and design: DUC, HUT, and CK; analysis and interpretation of data: DUC, HUT, DA, and CK; drafting of the manuscript: DUC, HUT, DA, and CK, critically revision of the manuscript for important intellectual content: DUC, HUT, DA, and CK; final approval of the version to be published: DUC, HUT, DA, and CK.

\section{Compliance with ethical standards}

Conflict of interest The authors declare that they have no conflict of interest.

Ethical approval All procedures performed in this study were made according to ethical standards of the institutional and/or national research committee.

Informed consent Written informed consent was obtained from the patient for publication of this case-based review.

\section{References}

1. Benson MD, Buxbaum JN, Eisenberg DS, Merlini G, Saraiva MJM, Sekijima Y, Sipe JD, Westermark P (2018) Amyloid nomenclature 2018: recommendations by the International 
Society of Amyloidosis (ISA) nomenclature committee. Amyloid 25:215-219

2. Picken MM (2020) The pathology of amyloidosis in classification: a review. Acta Haematol 11:1-13. https://doi.org/10.1159/00050 6696 (Online ahead of print)

3. Pinney JH, Smith CJ, Taube JB et al (2013) Systemic amyloidosis in England: an epidemiological study. Br J Haematol 161:525-532

4. Kaşifoglu T, Bilge SY, Sari I et al (2014) Amyloidosis and its related factors in Turkish patients with familial Mediterranean fever: a multicentre study. Rheumatology 53:741-745

5. Takimoto Y, Kogiku A, Konda E, Samoto T, Ishihara M, Yamashita T (2020) Primary localized amyloidosis of the uterine cervix during pregnancy. J Obstet Gynaecol Res 46:787-790

6. Tsang WY, Chan JK (1993) Amyloid-producing squamous cell carcinoma of the uterine cervix. Arch Pathol Lab Med 117:199-201

7. Pehlivanov B, Belovegdov V, Ivanov G, Ivancheva H (2008) Primary localized amyloidosis of the vagina. Aust N Z J Obstet Gynaecol 48:120-122

8. Gibbons D, Lindberg GM, Ashfaq R, Saboorian MH (1998) Localized amyloidosis of the uterine cervix. Int J Gynecol Pathol 17:368-371

9. Lee JA, Angus B (1993) Amyloidosis of the uterine vessels: an unusual cause of menorrhagia. Br J Obstet Gynaecol 100:1056-1057

10. Taylor E, Gilks B, Lanvin D (2001) Amyloidosis of the uterine cervix presenting as postmenopausal bleeding. Obstet Gynecol 98:966-968

11. Copeland W Jr, Hawley PC, Teteris NJ (1985) Gynecologic amyloidosis. Am J Obstet Gynecol 153:555-556
12. Winkler DD, Emery JA, Alan CB (2004) Amyloidosis of the endometrium: an asymptomatic presentation. Obstet Gynecol 104:1144-1147

13. Yue CC, Lampman JH, Park CH, Ballou SP (1983) Secondary amyloidosis: diagnosis from an endometrial biopsy. Arthritis Rheum 26:1295-1296

14. Gasparyan AY, Ayvazyan L, Blackmore H, Kitas GD (2011) Writing a narrative biomedical review: considerations for authors, peer reviewers, and editors. Rheumatol Int 31:1409-1417

15. Bustamante JG, Zaidi SRH (2020) Amyloidosis. In: StatPearls. Treasure Island: StatPearls Publishing

16. Lane T, Pinney JH, Gilbertson JA et al (2017) Changing epidemiology of AA amyloidosis: clinical observations over 25 years at a single national referral centre. Amyloid 24:162-166

17. Ozdogan H, Ugurlu S (2019) Familial Mediterranean fever. Presse Med 48:e61-e76

18. Jongen VH, Grond AJ, van Veelen H, Santema JG (1998) Uterine amyloidosis in menopause. Br J Obstet Gynaecol 105:362-364

19. Korkmaz C, Kebapçi M (2004) Addison's disease is associated with widespread abdominopelvic visceral calcification due to secondary amyloidosis: a case report. Acta Radiol 45:800-802

20. Sucker C, Hetzel GR, Grabensee B, Stockschlaeder M, Scharf RE (2006) Amyloidosis and bleeding: pathophysiology, diagnosis, and therapy. Am J Kidney Dis 47:947-955

Publisher's Note Springer Nature remains neutral with regard to jurisdictional claims in published maps and institutional affiliations. 